\title{
Nocturnal air, road, and rail traffic noise and daytime cognitive performance and annoyance ${ }^{\text {a) }}$
}

\author{
Eva-Maria Elmenhorst, ${ }^{\text {b) }}$ Julia Quehl, Uwe Müller, and Mathias Basner ${ }^{\text {c) }}$ \\ DLR-German Aerospace Center, Institute of Aerospace Medicine, 51170 Cologne, Germany
}

(Received 15 May 2013; revised 14 November 2013; accepted 25 November 2013)

\begin{abstract}
Various studies indicate that at the same noise level and during the daytime, annoyance increases in the order of rail, road, and aircraft noise. The present study investigates if the same ranking can be found for annoyance to nocturnal exposure and next day cognitive performance. Annoyance ratings and performance change during combined noise exposure were also tested. In the laboratory 72 participants were exposed to air, road, or rail traffic noise and all combinations. The number of noise events and $L_{\mathrm{AS} \text {,eq }}$ were kept constant. Each morning noise annoyance questionnaires and performance tasks were administered. Aircraft noise annoyance ranked first followed by railway and road noise. A possible explanation is the longer duration of aircraft noise events used in this study compared to road and railway noise events. In contrast to road and rail traffic, aircraft noise annoyance was higher after nights with combined exposure. Pooled noise exposure data showed small but significant impairments in reaction times $(6 \mathrm{~ms})$ compared to nights without noise. The noise sources did not have a differential impact on performance. Combined exposure to multiple traffic noise sources did not induce stronger impairments than a single noise source. This was reflected also in low workload ratings. (C) 2014 Acoustical Society of America. [http://dx.doi.org/10.1121/1.4842475]
\end{abstract}

PACS number(s): 43.50.Lj, 43.50.Rq, 43.50.Qp [SF]

Pages: 213-222

\section{INTRODUCTION}

Activities such as communication, relaxation, and recuperation are considered to be especially sensitive to disturbances by noise. The disturbance of sleep is one of the most common reasons for noise complaints (Guski, 1991). Nocturnal traffic noise interrupts the physiological sleep structure. Even though the sleeper is unconscious, noise events may cause accelerations of heart rate and EEG frequency, and may induce sleep stage changes to light sleep and awakenings. As a secondary effect performance can be impaired, and chronic noise exposure may even promote negative long-term effects like cardiovascular diseases (Babisch, 2011; Jarup et al., 2008).

A glossary of acoustical parameters is given in Table I. Data from regularly conducted surveys by the German Federal Environmental Agency indicate that about half of the population in Germany is exposed to road traffic noise at levels $\left(L_{\mathrm{Aeq}, \mathrm{d}}\right.$ above $\left.55 \mathrm{dBA}\right)$ at which impairments of physical and social well-being are to be expected (Ortscheid and Wende, 2002a,b). Regarding rail traffic the percentage is approximately $20 \%$. The acoustic exposure of the population

\footnotetext{
a) Parts of the cognitive performance data were published in Basner, M., Mueller, U., and Elmenhorst, E. M. (2011). "Single and combined effects of air, road, and rail traffic noise on sleep and recuperation," Sleep 34, 11-23 and parts of the annoyance data in Quehl, J., and Basner, M. (2008). "Nächtlicher Flug-, Straßen- und Bahnlärm: Belästigungsunterschiede und kumulative Wirkungen" ("Nocturnal air, road and rail traffic noise: differences in annoyance and cumulative effects"), Z. Lärmbekämpfung 6, 240-245.

b) Author to whom correspondence should be addressed. Electronic mail: eva-maria.elmenhorst@dlr.de

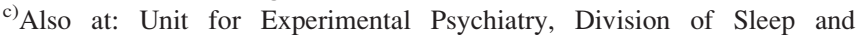
Chronobiology, University of Pennsylvania Perelman School of Medicine, 1013 Blockley Hall, 423 Guardian Drive, Philadelphia, PA 19104-6021.
}

(western areas of Germany) to road and rail traffic at many sites is high even during the night (German Federal Environmental Agency 2009 citing Ortscheid and Wende, 2002a,b). For instance, during the night about half of the population is exposed to road traffic noise levels $\left(L_{\text {Aeq, }}>45 \mathrm{dBA}\right)$ at which sleep disturbance must be expected with opened windows (Berglund et al., 2000). Concerning rail traffic the proportion is about $37 \%$. Like most noise surveys the cited noise exposure levels refer to outdoor measurements. However, a recent field comparison of indoor and outdoor road traffic noise exposure showed that sounds of domestic activity also play an important role for indoor noise exposure (Fidell et al., 2013).

Often, noise annoyance studies focus on subjects who are distributed in the upper $25 \%$ to $30 \%$ of the answering scale (on a five-point scale the categories 4 and 5), the so-called "highly annoyed" (HA). The lower limit of this domain is internationally used as a minimum value for individual high annoyance (e.g., Fidell et al., 1991; Miedema and Vos, 1998; Schultz, 1978). Recommended dose-response curves for transportation noises-road, rail, and air trafficfor annoyed individuals $(50 \%)$ are described in the recent European Environment Agency report 11/2010 (2010). Miedema and Vos (1998) compared the relationship between the percentage of HA persons and aircraft, rail, and road traffic noise exposure (see also Fields and Walker, 1982; Fidell et al., 1991; Miedema and Oudshoorn, 2001). In general, annoyance shows a statistically monotonic relationship with $L_{\text {eq }}$. However, with an equal level increase in $L_{\mathrm{DN}}$ more persons feel highly annoyed by aircraft noise than by road and rail traffic noise. Regarding the latter two exposures, the road traffic noise curve ranks above the curve for rail traffic noise (see also Guski et al., 2004). Hence, aircraft noise has the highest annoyance potential compared to other traffic 


\begin{tabular}{ll}
\hline \hline $\mathrm{CTL}$ & Day-night average sound level at which half of the respective population is highly annoyed (Fidell et al., 2011) \\
$L_{\mathrm{A}, \mathrm{max}}$ & Maximum sound pressure level, defined as the highest noise level in a given recording period, A-weighted. \\
$L_{\mathrm{AS}, \max }$ & $L_{\mathrm{A}, \max }$ with time constant set to slow \\
$L_{\mathrm{eq}}$ & Energy equivalent sound level, calculated by integrating sound energy from all noise events during a given time period \\
$L_{\mathrm{Aeq}}$ & A-weighted $L_{\mathrm{eq}}$ \\
$L_{\mathrm{Aeq}, \mathrm{d}}$ & $L_{\mathrm{Aeq}}$ calculated during the daytime \\
$L_{\mathrm{Aeq}, \mathrm{n}}$ & $L_{\mathrm{Aeq}}$ calculated during the nighttime \\
$L_{\mathrm{ASeq}}$ & $L_{\mathrm{Aeq}}$ with time constant set to slow \\
$L_{\mathrm{DN}}$ & $L_{\mathrm{eq}}$ for day and night, while the night receives a penalty of $10 \mathrm{~dB}$ \\
\hline \hline
\end{tabular}

noises with similar sound energy, and these differences increase with growing sound level.

Griefahn et al. (2006) compared the effects of road, rail, and aircraft noise and tested the suitability of the equivalent sound level for the evaluation of sleep disturbances. Subjectively rated sleep quality decreased with the equivalent sound level, whereas most physiological variables revealed the same reactions to both the lower and considerably stronger reactions to the highest acoustic exposure. Aircraft, rail, and road traffic noise induced similar aftereffects but physiological sleep parameters were most severely influenced by rail noise. The authors concluded that the equivalent sound level seems to be a suitable predictor for subjectively assessed sleep quality but not for physiological sleep disturbances. Basner et al. (2011) have reported that road traffic noise had the highest impact on sleep structure and continuity, whereas the subjective evaluation of sleep was worse after nights with air and rail traffic noise exposure. In a field study on nocturnal rail and aircraft noise, awakening probability increased with increasing $L_{\mathrm{AS} \text {,max }}$, and rail traffic led to a higher awakening probability than aircraft noise exposure (Elmenhorst et al., 2012). Comparing daytime, nighttime, and around the clock noise exposure, around the clock noise shows the strongest impact on performance followed by night-time noise (Hoeger, 2004). To date, effects of night-time traffic noise on cognitive performance the following day have been inconsistent. The number of noise events during the night, $L_{\mathrm{AS} \text {, max }}$ of noise events, as well as $L_{\mathrm{AS} \text {,eq }}$ have been proposed as important acoustical factors (Bonnefond et al., 2008; Öhrstrom, 1995; Wilkinson and Campbell, 1984). Reaction time impairments have been found in a study on pooled data of road, rail, and aircraft noise (Marks and Griefahn, 2007). Elmenhorst et al. (2010) have reported significant exposure-response relationships of performance decrements depending on number of nocturnal noise events as well as $L_{\mathrm{AS} \text {,eq. }}$ Several studies, however, did not observe performance declines caused by road, rail, or aircraft noise (Griefahn et al., 2000; Marks and Griefahn, 2005; Schapkin et al., 2006). Breimhorst et al. (2009) hypothesized that the small or even not at all detectable performance impairments after nocturnal traffic noise exposure was a result of increased effort during the execution of the tasks. However, blink rate as a measure of effort did not decrease while conducting the performance tests in relation to the nocturnal noise exposure. Recently, Matheson et al. (2010) stated that nighttime noise does not seem to add to performance impairments caused by daytime noise exposure in schoolchildren.

Exposure to multiple traffic noise sources is a major problem. Especially residents living along railway lines and near airports are affected by exposure to two or even three traffic noise sources simultaneously. According to the German Federal Environmental Agency (2009) (Ortscheid and Wende, 2002a,b), about $47 \times 10^{6}$ residents in Germany are annoyed by road traffic noise, about $13 \times 10^{6}$ are additionally annoyed by aircraft noise, and about $11 \times 10^{6}$ by railway noise (Ortscheid and Wende, 2001). So far, there are no binding regulations concerning the assessment of noise situations in which more than one noise source exists (Tegeder, 2001). However, there is a guideline of VDI (Association of German engineers) which handles the parameters characterizing annoyance from multiple sound sources (VDI 3722, 2013). It is assumed that a noise situation with multiple traffic noises is more annoying than a situation with only one noise source. However, the evaluation of the whole situation is not simply additive, since the source specific dose-response curves indicate different reactions to individual traffic noise sources at the same acoustic energy. Accordingly, Oliva (1998) pointed out that the single noise sources cannot be integrated into a "holistic noise scenery," since annoyance is reflected in the individual sound evaluations which are influenced by acoustic characteristics as well as non-acoustic factors being at least as important as the noise exposure itself (Evans and Lepore, 1997; Fields, 1993; Stallen, 1999).

Studies on combined effects of different traffic noise sources are still rare. Objectives of the present study were to compare the effects of aircraft, road, and rail noise, separately and in combination, on daytime cognitive performance and annoyance. The aims of the study were (1) to investigate if the same differences in annoyance between traffic noise sources can be found for nocturnal noise exposure as for daytime exposure, (2) to analyze if annoyance ratings regarding road, rail, and aircraft noise can change (i.e., be amplified or reduced) due to the existence of a second or third traffic noise, and (3) to study if the combination of more than one traffic noise source during the night leads to stronger impairments in daytime cognitive performance than the exposure to only a single traffic noise. In comparison to the exposure to only one traffic noise source, we investigated whether combined effects were more or less than additive. 


\section{METHODS}

\section{A. Design and acoustical measures}

The study was designed to investigate and compare the three different traffic noise sources—air (AI), road (RO), and rail (RA) traffic - under equal exposure conditions regarding number of traffic noise events, maximum sound pressure level [sound pressure level (SPL): $\left.L_{\mathrm{AS} \text {,max }}\right]$ or average equivalent sound level $\left(L_{\mathrm{AS}, \mathrm{eq}}\right)$. All sounds and SPLs (sampling rate $0.125 \mathrm{~s}$ ) were recorded with a class-1 sound level meter NC10 (Cortex Instruments, DIN IEC 651) inside residents' buildings with open or closed windows. SPL measurements were A-weighted with the time constant set to "slow." The distances to the noise source were selected in a way that the maximum level of the recorded sounds differed not more than $2 \mathrm{~dB}(\mathrm{~A})$ from the intended noise categories of the study design. Details regarding acoustic characteristics of the noises are given in Table II. Nine different exposure patterns were applied during the nine nights of each of the nine study periods leading to a complete crossover design.

(1) Three single exposure nights with 40 noise events of either aircraft, road or rail traffic noise $(5 \times 8$ noise events with a maximum SPL of $45,50,55,60$, or $65 \mathrm{dBA}$ per traffic noise source): AI, RO, RA.

(2) A single exposure night with 80 road traffic noise events at an $L_{\mathrm{AS} \text {,eq }}$ equivalent to the single exposures to aircraft and rail traffic noise: RORO.

(3) Three double exposure nights (aircraft and road traffic noise, aircraft and rail traffic noise, road and rail traffic noise) with 80 noise events each (40 per traffic noise source): AIRO, AIRA, RORA.

(4) One triple exposure night with all three traffic noise sources with a total of 120 traffic noise events (40 per traffic noise source): AIRORA.

(5) A noise-free baseline condition had a background $L_{\mathrm{AS} \text {,eq }}$ of $30 \mathrm{~dB}$ caused by the $\mathrm{A} / \mathrm{C}$ system of the sleep laboratory: NO.

Each rail noise $\mathrm{dB}$-category consisted of four noise events from freight trains and four from passenger trains. Each road noise dB-category included five noise events from passenger cars with dry roads, one event from passenger cars with wet roads, one event from motorcycles, and one event from trucks. Each aircraft noise dB-category consisted of eight noise events from jet aircraft that were recorded in the vicinity of the Cologne/Bonn airport. They were not further divided with respect to take-off or landing. The single exposure nights of rail and air traffic were identical concerning $L_{\mathrm{AS} \text {,eq }}$. Because of the shorter duration of road traffic noise events, $L_{\mathrm{AS} \text {,eq }}$ of the road traffic single exposure night was lower. In order to gain the identical $L_{\mathrm{AS} \text {,eq }}$ for the road traffic single exposure night as well, the number of road noise events was doubled in the exposure night RORO. In that way, it was possible to compare single exposure nights according to the $L_{\mathrm{AS} \text {,eq }}$ (Table III). In order to be able to balance the study design, i.e., that each exposure was applied in each study night position once, there were nine study periods with eight different subjects in each study period. Each period contained all exposure conditions.

The length of the time interval between two noise events differed depending on the number of noise events per night and was otherwise randomly chosen using block randomization techniques. In nights with 40 noise events the time interval ranged between 3 to $21 \mathrm{~min}$, in nights with 80 noise events between 3 to $9 \mathrm{~min}$, and in the night with 120 noise events between 3 to $5 \mathrm{~min}$. Furthermore, the length of time intervals between two noise events was evenly distributed over the night to avoid clusters of short or long time intervals at the beginning or the end of the night. Therefore, the night was divided into four blocks with equal number of noise events. Time intervals of similar length were then assigned to the four blocks and randomly distributed within each block. A similar procedure was applied for maximum SPL of noise events. The noise playback started at a predefined point of time after the beginning of the time in bed period, which was after twelve minutes for the single exposure nights, after six minutes for the double exposure nights and after four minutes for the triple exposure night. The study was conducted double-blind; i.e., neither the investigators nor the subjects were aware of the exposure pattern of the night.

\section{B. Participants}

Seventy-two volunteers aged between 18 and $71 \mathrm{yr}$ [mean age $40 \pm 13(\mathrm{SD})$ years] participated in the study, 40

TABLE II. Acoustic characteristics of noise events for the traffic noise sources air (AI), road (RO), and rail (RA) traffic. OE = midpoints of octave energy, $\mathrm{SD}=$ standard deviation.

\begin{tabular}{lccr}
\hline \hline & \multicolumn{1}{c}{ AI } & RO & $\begin{array}{c}\text { RA } \\
\text { Acoustic characteristics }\end{array}$ \\
\hline SPL rise time (dB/s) & Mean (SD, range) & Mean (SD, range) & $7.1(2.6,2.3-12.7)$ \\
Noise duration (s) & $3.6(1.1,1.2-5.8)$ & $6.3(1.9,3.1-13.6)$ & $25.9(7.9,14.0-46.4)$ \\
$31.5 \mathrm{~Hz}(\mathrm{~dB}) \mathrm{OE}$ & $66.0(16.6,36.8-109.5)$ & $20.5(7.2,9.1-38.1)$ & $62.5(4.8,52.9-70.1)$ \\
$63 \mathrm{~Hz}(\mathrm{~dB}) \mathrm{OE}$ & $44.6(6.9,34.4-63.4)$ & $43.4(6.2,32.8-61.2)$ & $59.9(5.9,43.2-71.0)$ \\
$125 \mathrm{~Hz}(\mathrm{~dB}) \mathrm{OE}$ & $47.8(5.9,37.9-60.4)$ & $48.6(8.4,33.1-68.6)$ & $52.3(6.8,36.6-66.8)$ \\
$250 \mathrm{~Hz}(\mathrm{~dB}) \mathrm{OE}$ & $45.4(5.9,35.9-63.3)$ & $40.9(9.7,24.8-67.5)$ & $51.1(7.7,36.7-64.6)$ \\
$500 \mathrm{~Hz}(\mathrm{~dB}) \mathrm{OE}$ & $46.1(5.6,37.7-62.6)$ & $37.6(6.8,26.2-51.4)$ & $47.1(7.2,33.1-61.4)$ \\
$1 \mathrm{kHz}(\mathrm{dB}) \mathrm{OE}$ & $46.0(5.2,37.9-56.6)$ & $40.0(7.0,29.1-54.0)$ & $42.0(6.5,28.5-54.9)$ \\
$2 \mathrm{kHz}(\mathrm{dB}) \mathrm{OE}$ & $41.8(32.6,32.4-52.7)$ & $45.0(5.8,36.2-55.0)$ & $39.4(7.2,25.9-53.9)$ \\
$4 \mathrm{kHz}(\mathrm{dB}) \mathrm{OE}$ & $32.6(6.9,21.3-45.1)$ & $40.6(6.3,30.6-51.9)$ & $32.6(8.2,18.3-46.1)$ \\
$8 \mathrm{kHz}(\mathrm{dB}) \mathrm{OE}$ & $18.1(6.6,9.5-30.6)$ & $30.1(5.5,22.0-42.2)$ & $18.1(5.6,11.6-37.0)$ \\
\hline \hline
\end{tabular}


TABLE III. Composition of exposure nights ( $\mathrm{NO}=$ noise-free control night, $\mathrm{AI}=$ aircraft noise, $\mathrm{RO}=\mathrm{road}$ traffic noise, $\mathrm{RA}=$ rail traffic noise, $\mathrm{RORO}=80$ road traffic noises with a $L_{\mathrm{AS} \text {,eq }}$ equal to $\mathrm{AI}$ and $\mathrm{RA}$, $\mathrm{AIRO}=$ aircraft plus road traffic noise, AIRA = aircraft plus rail traffic noise; $\mathrm{RORA}=$ road plus rail traffic noise, AIRORA = aircraft plus road plus rail traffic noise).

\begin{tabular}{lcc}
\hline \hline Noise pattern & Number of noise events per night & $L_{\mathrm{AS}, \mathrm{eq}}[\mathrm{dB}(\mathrm{A})]$ \\
\hline AI & 40 & 39.7 \\
RO & 40 & 36.9 \\
RA & 40 & 39.7 \\
RORO & 80 & 39.7 \\
AIRO & 80 & 41.2 \\
AIRA & 80 & 42.5 \\
RORA & 80 & 41.2 \\
AIRORA & 120 & 43.3 \\
NO & 0 & 30.0 \\
\hline \hline
\end{tabular}

were female. Participants passed through a multi-stage selection procedure including questionnaires, medical examination, and training of computer-assisted performance tests. Only healthy volunteers participated who did not suffer from intrinsic sleep disorders and had a normal hearing threshold according to their age. Subjects received reimbursement for participation. All subjects signed an informed consent according to the Declaration of Helsinki. The Ethics Committee of the North Rhine Medical Board approved the study.

\section{Procedure}

The study took place in the occupational medical simulation facility (AMSAN) of the German Aerospace Centre (DLR); i.e., a sleep laboratory consisting of eight sleep cabins. Subjects were investigated for eleven consecutive nights. Night one was noise-free and served as adaptation to the unfamiliar environment and the measuring devices (sleepEEG). In nights 2-10, subjects were exposed to different noise exposure patterns including a silent baseline condition. Night 11 served as recovery and back-up night and was excluded from data analysis. During the study period, subjects stayed in the laboratory from $7 \mathrm{pm}$ until $8 \mathrm{am}$, during the day they were free to go on with their usual daily activities. The beginning of the sleep period was scheduled for $11 \mathrm{pm}$; a nightly time in bed of exactly $8 \mathrm{~h}$ was kept. Naps during the day were prohibited and compliance was controlled with actigraphic monitoring.

Traffic noise of air, road, and rail traffic was presented via loudspeakers in each private sleeping room. Acoustically calibrated sleep cabins guaranteed a correct playback of the original traffic noise events.

\section{Survey}

\section{Cognitive performance measures}

Participants performed computer-assisted cognitive performance tests in the morning. The tasks were implemented on the test-software ERTS (experimental run time system) of the Berisoft Company. Participants trained the tests 24 times in the run-up of the study to reduce training effects and guarantee stable performance levels. To minimize effects due to motivation, they were asked to perform the tests as quickly and accurately as possible with constant effort.

a. Psychomotor vigilance task (PVT). Participants performed a PVT with 10 min duration (inter-stimulus interval: $1.5-10 \mathrm{~s}$ ). A white digital stopwatch (that showed the time in $\mathrm{ms}$ ) lighting up on the dark computer screen served as stimulus. Participants had to respond by pressing a key as fast as possible. The number of presented signals depended on the reaction times of the participant. Reaction times $\geq 500 \mathrm{~ms}$ were regarded as lapses (Dinges and Powell, 1985). The test timed out after $1 \mathrm{~s}$. Reaction times $\leq 130 \mathrm{~ms}$ were most probably reactions without stimulus (false starts) and therefore excluded from the analysis. Mean reaction time was calculated excluding reaction times from lapses.

b. Memory search task (MST). Four letters had to be memorized without time pressure at the beginning of the task. In a 3 min recall phase letters of the whole alphabet were presented. The participant had to decide whether the current letter belonged to the learning set or not by using two predefined keys. Reaction times were recorded. Reaction times that were faster than $130 \mathrm{~ms}$ were regarded as false responses and excluded from analysis. The task belongs to the AGARD STRES battery (AGARD, 1989).

c. NASA task load index (TLX). NASA TLX is a questionnaire asking for the subjective and retrospective evaluation of workload (Hart and Staveland, 1988). The scale ranges from 0 points (very low workload) to 20 points (very high workload). Furthermore, each participant provides a personal ranking of the importance of the questions ranging from 5 (very important) to 0 (not important). Scale value and rank importance were multiplied and summed up to get a single value. Workload was then grouped into five categories (covering 60 points each) from 0 points (very low work load) to 300 points (very high workload).

\section{Annoyance measures}

After having performed the cognitive test battery questionnaire surveys were conducted. Subjects were asked which traffic noises they had perceived during the night. The first question was: "Did you hear aircraft noise last night?" (answer alternatives: $1=$ no, $2=$ yes). Only when subjects answered this question with "yes" were more questions concerning the impact of aircraft noise asked (e.g., concerning the aircraft noise annoyance). The perception and evaluation of rail and road traffic noise followed similarly. If subjects perceived the noise of two or three traffic noise sources they were asked by which of these sources they were more annoyed (two traffic noises) or most annoyed (three traffic noises).

Annoyance due to nocturnal road, railway and aircraft noise was rated using a five-point scale (from " $1=$ not" to "5 = very" annoyed) according recommendations of Team 6 of the International Commission on Biological Effects of Noise (ICBEN) (Felscher-Suhr et al., 2000; Fields et al., 2001). 


\section{RESULTS}

\section{A. Direct comparison of nocturnal aircraft, road, and rail traffic noise and annoyance}

Figure 1 depicts the perception of the three traffic noise sources depending on the nocturnal exposure. It is apparent that the perception of a specific traffic noise occurred more often after night with the corresponding exposure (aircraft noise: AI, AIRA, AIRO, AIRORA, road traffic noise: RO, RORO, RORA, AIRO, AIRORA, rail traffic noise: RA, AIRA, RORA, AIRORA). Obviously, AI was recognized very well (94\% correct answers), whereas RA was more often confused with other traffic noise sources (78\% correct answers). However, sometimes participants perceived a specific traffic noise that had in fact not been presented the night before. For instance, 39\% heard aircraft noise in the condition RA. The following statistical analyses are based on the nights in which the presented traffic noises were perceived correctly by the participants. (Analyses of the complete dataset revealed the same ranking except for the comparison road vs rail traffic.)

Each morning subjects were asked which traffic noises they had perceived during the night. If it was the noise of two or three traffic noise sources they were asked by which of these sources they were more annoyed (two traffic noises) or most annoyed (three traffic noises) (Fig. 2). In a direct comparison of double and triple exposure nights, aircraft noise annoyed more than railway noise (68\% vs $32 \%)$ and more than road traffic noise ( $73 \%$ vs $27 \%$ ). Even in nights with all three traffic noises, aircraft noise was most annoying (70\% vs $13 \%$, respectively, $17 \%$ ). In a direct comparison between rail and road traffic noise, subjects felt more annoyed by railway noise (64\% vs $36 \%$ ).

\section{B. Combined effects of nocturnal aircraft, road, and rail traffic noise and annoyance}

The nine exposure patterns were analyzed with Friedman tests. Significant effects on the annoyance ratings

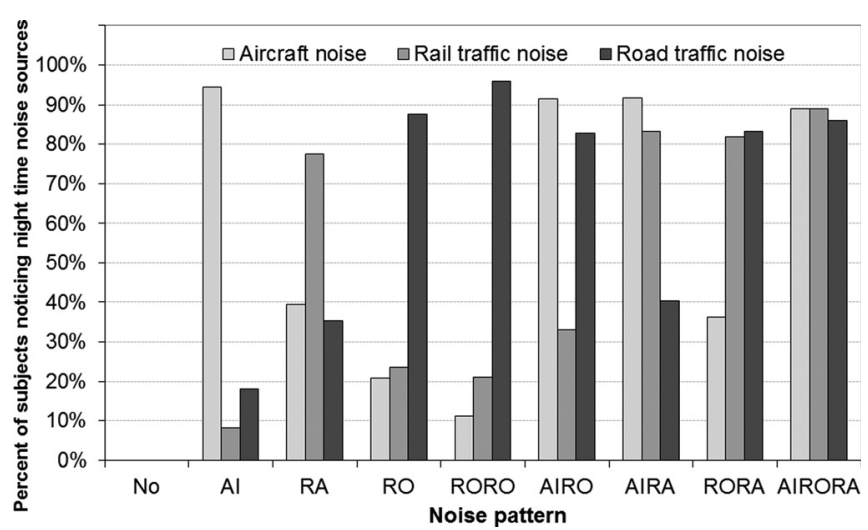

FIG. 1. Percentage of participants who perceived night time noise sources depending on the exposure pattern. [Questions: "Did you hear aircraft noise last night?" $\rightarrow$ answer: yes (light gray); "Did you hear rail traffic noise last night?" $\rightarrow$ answer: yes (middle gray), "Did you hear road traffic noise last night?" $\rightarrow$ answer: yes (dark gray).] $\mathrm{NO}=$ condition without noise, $\mathrm{AI}=40$ aircraft noise events, $\mathrm{RA}=40$ rail traffic noise events, $\mathrm{RO}=40$ road traffic noise events and combinations (e.g., AIRA: 40 aircraft noise events plus 40 rail traffic noise events).

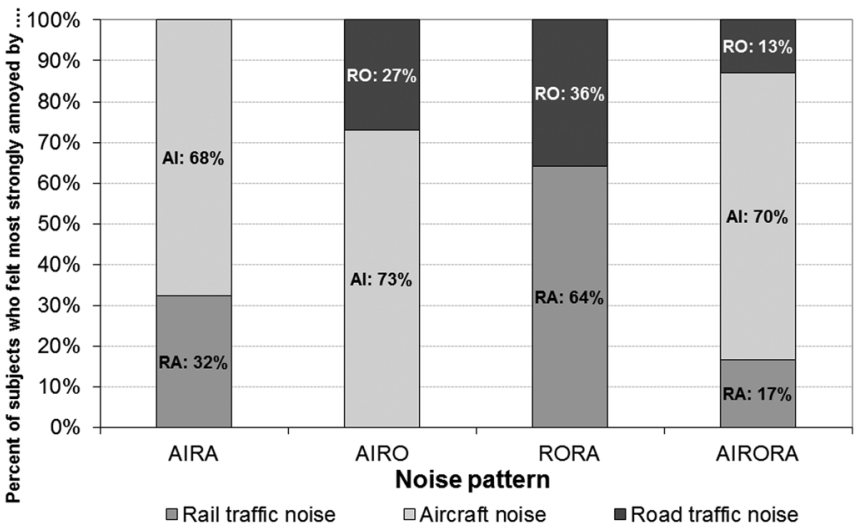

FIG. 2. Frequency distribution of participants who felt most strongly annoyed depending on the nocturnal exposure. (Questions: "By which traffic noise type have you been MORE STRONGLY annoyed during the past night?," respectively, "By which traffic noise type have you been MOST STRONGLY annoyed during the past night?") $\mathrm{AI}=40$ aircraft noise events, $\mathrm{RA}=40$ rail traffic noise events, $\mathrm{RO}=40 \mathrm{road}$ traffic noise events, and combinations (e.g., AIRA: 40 aircraft noise events plus 40 rail traffic noise events).

were found due to aircraft noise $\left(\chi_{(3,0.003)}^{2}=14.057\right)$ and road traffic noise $\left(\chi^{2}(4,0.003)=16.172\right)$, but not for railway noise annoyance $\left(\chi_{(3,0.069)}^{2}=7.100\right)$.

According to the Schultz criterion (Schultz, 1978), in Figs. 3 and 4, the original five-point answering scales were combined in terms of gray shades. Categories 4 and 5 (high to very high annoyance: dark grays) as well as categories 1 to 3 (none to moderate noise annoyance: white and light grays) were pooled. The frequency distribution of annoyance due to aircraft and road traffic noise depending on the nocturnal exposure is illustrated. Figure 3 shows that aircraft noise annoyance was highest in the conditions AIRA (46\%) and AIRORA (43\%). These were followed by patterns AIRO and AI with a percentage of $40 \%$ and $28 \%$ highly annoyed. In the paired comparisons (using the answers of

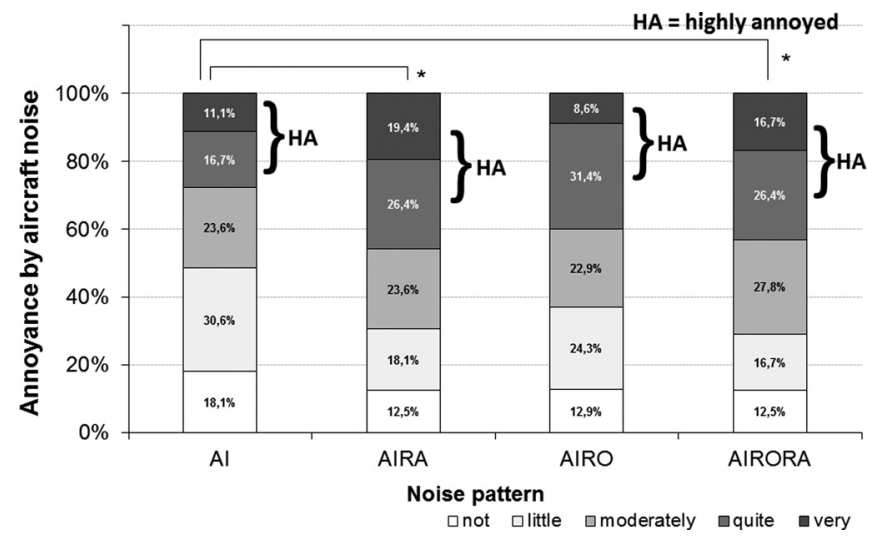

FIG. 3. Frequency distribution of participants who felt annoyed by aircraft noise on a five-point scale $(1=$ not to $5=$ very annoyed, depicted as five stacks; white and light grays: not to moderately annoyed, dark grays: quite and very annoyed $=\mathrm{HA}=$ highly annoyed) depending on the nocturnal exposure. (Question: "How much have you been annoyed by aircraft noise during the past night?" Significant difference in Wilcoxon tests with *, $p<0.008$.) $\mathrm{AI}=40$ aircraft noise events, $\mathrm{RA}=40$ rail traffic noise events, $\mathrm{RO}=40$ road traffic noise events, and combinations (e.g., AIRA: 40 aircraft noise events plus 40 rail traffic noise events). 


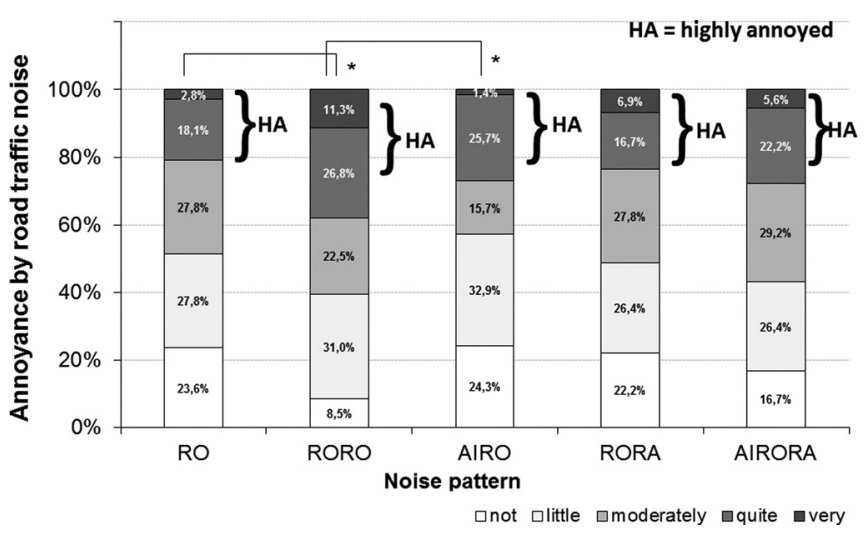

FIG. 4. Frequency distribution of participants who felt annoyed by road traffic noise on a five-point scale $(1=$ not to $5=$ very annoyed, depicted as five stacks; white and light grays: not to moderately annoyed, dark grays: quite and very annoyed $=\mathrm{HA}=$ highly annoyed) depending on the nocturnal exposure. (Question: "How much have you been annoyed by road traffic noise during the past night?" Significant differences with *, $p<0.005$.) AI $=40$ aircraft noise events, $\mathrm{RA}=40$ rail traffic noise events, $\mathrm{RO}=40$ road traffic noise events, and combinations (e.g., AIRO: 40 aircraft noise events plus 40 road traffic noise events).

the original five-point annoyance scale), AIRA and AIRORA differed significantly from AI. In both cases, the combination induced a significantly higher annoyance due to aircraft noise. This means that a situation with multiple traffic noise sources was significantly more annoying than a situation with only aircraft noise. Therefore, an amplification of aircraft noise annoyance due to the existence of a second or third traffic noise has been affirmed.

In Fig. 4 the percentage of HA due to road traffic noise was highest in the conditions RORO (38\%), AIRORA (28\%), and AIRO (27\%). These were followed by patterns RORA (24\%), and RO (21\%). The paired comparisons demonstrate significant differences between RO vs RORO as well as between AIRO vs RORO. In both cases, the condition RORO (80 road traffic noises with a $L_{\mathrm{AS} \text {,eq }}$ equal to AI and RA) induced a significantly higher percentage of HA. In other words, RORO with a $L_{\mathrm{AS} \text {,eq }}$ equal to $\mathrm{AI}$ and RA caused a significantly higher annoyance than RO or AIRO. Thereby the relevance of the frequency of nocturnal traffic movements for road traffic annoyance is stressed since the number of road noise events in the RORO pattern was twice as high as the number of noise events in the RO and AIRO conditions.

\section{General effects of nocturnal aircraft, road, and rail traffic noise and cognitive performance}

Mixed model analysis of variance (ANOVA) in SAS (version 9.2) was used for statistical analyses of performance data. Post hoc tests were adjusted for $\alpha$-inflation according to Dunnett or Tukey respectively. For the MST, hit rate (correct yes response on a signal trial), false alarm rate (incorrect yes response on a noise trial), sensitivity [measure of detection accuracy varying between 0.5 (signals are not differentiated from noise trials) and 1.0 (correct separation of signal and noise trials)] and bias [ranging between -1 (yes response to all trials) and +1 (no response to all trials), with 0 representing the absence of response bias] were calculated according to the non-parametric signal detection theory. Table IV presents an overview on daytime performance after the adaptation night, the baseline night, and the noise patterns (pooled data of days after noise exposure nights). Reaction time in PVT was significantly impaired after noise exposure. This effect was more pronounced comparing noise to adaptation, than comparing noise conditions to the in the cross over design included baseline condition suggesting cumulative carry-over effects from preceding noise exposure nights that are still present after one night without noise. Reaction time increased significantly both with an increasing number of noise events (40 noise events $4.5 \mathrm{~ms}$, 80 noise events $4.8 \mathrm{~ms}$, and 120 noise events $4.9 \mathrm{~ms}$ ) and with equivalent noise level $L_{\mathrm{AS} \text {,eq }}$ [between $4.8 \mathrm{~ms}\left(L_{\mathrm{AS} \text {,eq }} 36.9\right)$ and $\left.5.0 \mathrm{~ms}\left(L_{\mathrm{AS} \text {,eq }} 43.3\right)\right]$. MST did not show any significant differences. Subjects rated the subjective workload as being low under adaptation, baseline, and noise exposures.

\section{Combined effects of nocturnal aircraft, road, and rail traffic noise and cognitive performance}

Data were analyzed with mixed ANOVA in SAS (version 9.2) comparing the eight noise exposure conditions, baseline, and adaptation. Post hoc tests were adjusted for $\alpha$-inflation according to Dunnett or Tukey respectively. Figure 5 shows that performance was not especially influenced by one specific traffic noise source, or by single compared to combined traffic noise exposure, when $L_{\mathrm{AS} \text {, eq }}$, or number of noise events are kept constant. Significant effects between the noise exposure conditions were not found. In comparison to the adaptation, mean reaction time in PVT was significantly impaired after nights with the patterns AI $[8.9 \mathrm{~ms}( \pm 1.9 \mathrm{SE})$,

TABLE IV. Daytime cognitive performance after adaptation, baseline, and noise exposure conditions; significant differences with $p<0.05$. $\mathrm{PVT}=$ psychomotor vigilance task, MST $=$ memory search task, HR $=$ hit rate, FAR $=$ false alarm rate, $\mathrm{A}^{\prime}=$ sensitivity, TLX $=\mathrm{NASA}$ task load index, $\mathrm{SE}=$ standard error.

\begin{tabular}{|c|c|c|c|c|c|c|}
\hline Tests & $\begin{array}{l}\text { Adaptation (no noise) } \\
\text { Mean (SE) }\end{array}$ & $\begin{array}{c}\text { Baseline (no noise) } \\
\text { Mean (SE) }\end{array}$ & $\begin{array}{c}\text { Noise } \\
\text { Mean (SE) }\end{array}$ & $\begin{array}{c}\text { Noise vs adaptation } \\
p \text {-values }\end{array}$ & $\begin{array}{c}\text { Noise vs baseline } \\
p \text {-values }\end{array}$ & $\begin{array}{c}\text { Comparison of noise patterns } \\
\qquad p \text {-values }\end{array}$ \\
\hline PVT mean & $252.1 \mathrm{~ms}(3.8)$ & $254.5 \mathrm{~ms}(3.8)$ & $258.0 \mathrm{~ms}(3.6)$ & $<0.0001$ & 0.0233 & 0.0001 \\
\hline MST mean & $568.3 \mathrm{~ms}(13.5)$ & $581.4 \mathrm{~ms}(13.3)$ & $572.4 \mathrm{~ms}(12.0)$ & 0.8256 & 0.3527 & 0.8291 \\
\hline MST HR & $97.1 \%(0.5)$ & $96.9 \%(0.5)$ & $97.1 \%(0.3)$ & 0.9951 & 0.9118 & 0.9330 \\
\hline MST FAR & $2.1 \%(0.4)$ & $1.7 \%(0.3)$ & $1.4 \%(0.2)$ & 0.1107 & 0.6419 & 0.7676 \\
\hline MST A' & $0.9824(0.0032)$ & $0.9875(0.0031)$ & $0.9889(0.0013)$ & 0.1235 & 0.9058 & 0.8825 \\
\hline MST bias & $0.3139(0.0924)$ & $0.3232(0.0891)$ & $0.3849(0.0372)$ & 0.7393 & 0.7835 & 0.2689 \\
\hline TLX & $100.0(6.3)$ & $96.9(6.1)$ & $97.1(5.4)$ & 0.6773 & 0.9981 & 0.9161 \\
\hline
\end{tabular}




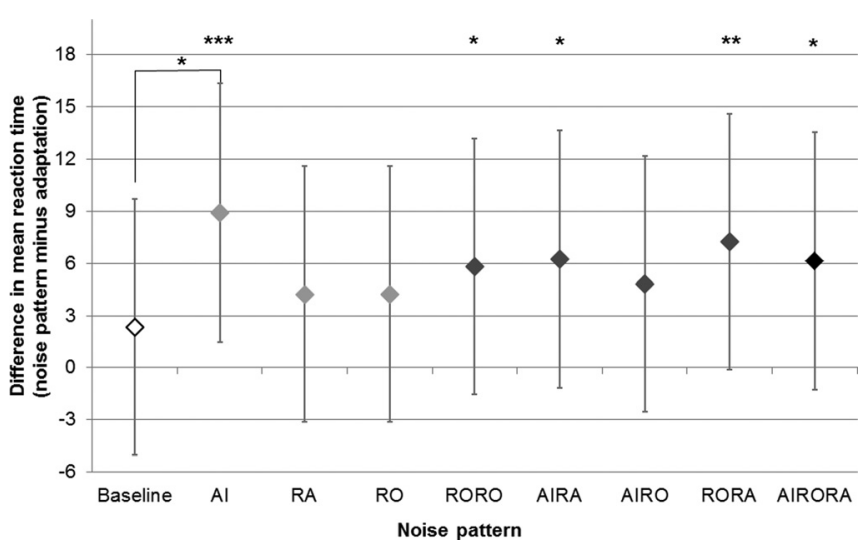

FIG. 5. Impairments in reaction time in the psychomotor vigilance task (PVT) under noise exposure as difference of mean reaction time under noise exposure minus the adaptation condition (without noise) with $95 \%$ confidence interval. Significant differences to adaptation are depicted with *, $p<0.05, * *, p<0.01, * * *, p<0.001$. Identification marks are grouped by number of noise events per exposure pattern: white $=$ without noise, light gray $=40$ noise events, dark gray $=80$ noise events, black $=120$ noise events. Baseline $=$ without noise, $\mathrm{AI}=40$ aircraft noise events, $\mathrm{RA}=40$ rail traffic noise events, $\mathrm{RO}=40$ road traffic noise events.

$p<0.0001$ ], RORO [5.8 ms ( $\pm 1.8 \mathrm{SE}$ ), $p=0.0483$ ), AIRA [6.2 ms ( $\pm 1.9 \mathrm{SE}), p=0.0287]$, RORA [7.2 $\mathrm{ms}( \pm 1.8 \mathrm{SE})$, $p=0.0030]$, and AIRORA [6.1 ms ( $\pm 1.9 \mathrm{SE}), p=0.0348$ ], whereas the comparison to baseline led to an increase in mean reaction time by $6.6 \mathrm{~ms}$ [ $( \pm 1.8 \mathrm{SE}), p=0.0124]$ due to the pattern AI only.

Mixed ANOVA of MST data and NASA TLX ratings did not show a significant omnibus effect of exposure condition (MST mean $p=0.8291$; NASA TLX $p=0.9161$, Table IV). Subjective workload stayed in the low category.

Mixed ANOVA with number of noise events as main factor (irrespective of the noise source) revealed that combined exposure nights ( 80 or 120 noise events) did not lead to stronger performance impairments than the single exposure conditions (40 noise events). Performance decrements in PVT due to single, double, and triple exposure patterns were less than additive; i.e., it was expected that doubling or tripling the number of noise events led to higher reaction times but this was not confirmed by the data. Subjective rating of workload (NASA TLX) was more than additive after double exposure nights, but less than additive after the triple exposure pattern.

\section{DISCUSSION}

\section{A. Nocturnal traffic noise and annoyance}

\section{A direct comparison of nocturnal aircraft, road, and rail traffic noise and annoyance}

When asked by which traffic noise of the previous night subjects felt MORE annoyed (two traffic noise sources heard) or MOST annoyed (three traffic noise sources heard), aircraft noise annoyance ranked first followed by the annoyance due to railway and road traffic noise. This is only partially consistent with previous dose-response curves according to which the road traffic noise annoyance curve lies above the railway noise annoyance curve. However, these curves apply to a $24 \mathrm{~h} L_{\mathrm{eq}}$ and not exclusively to nocturnal traffic noise exposure. Regarding the grand average community tolerance level (CTL), however, our results confirm the ranking of traffic noise annoyance. Schomer et al. (2012) found that annoyance is highest due to aircraft noise followed by conventional trains with vibration, road traffic, and finally trains without vibration. In direct comparison, the annoyance due to the single exposure pattern at a comparable equivalent sound level $L_{\mathrm{AS} \text {, eq }}$, RORO induced $38.1 \%$ of HA followed by the conditions AI (27.8\%) and RA (22.5\%). This ranking of noise sources causing annoyance has been reported previously for the German population (Ortscheid and Wende, 2004). The frequency of nocturnal traffic movements plays an important role since the number of noise events in RORO was twice as high as the number of noise events in the single patterns AI and RA. This is underlined by the fact that the exposure condition RO, however, at an $L_{\mathrm{AS} \text {,eq }}$, lower than $\mathrm{AI}$ and $\mathrm{RO}$ induced only a percentage of $21 \%$ HA. With numerous traffic noise events, it is more likely that an individual consciously perceives them during periods of intermittent wakefulness and falling asleep (Quehl and Basner, 2005, 2006).

A possible explanation for the observed ranking is the duration of the applied transportation noises. The duration of aircraft noise events exceeded the duration of road and railway traffic noise events. The assessment of annoyance following noise-induced sleep disturbances is based on the remembered and consciously experienced times awake and difficulties when falling asleep. The majority of awakenings lasted for one epoch (15 to $45 \mathrm{~s}$ ) and, therefore, was too short to be remembered the next day (Basner and Siebert, 2006). However, single awakenings were longer and, therefore, could be associated with the occurrence of waking consciousness. This might have induced an increased annoyance due to the consciously experienced aircraft noise events during intermittent wake periods or when subjects tried to fall asleep again, especially in nights with 80 or 120 noise events. As a consequence, longer awakenings may be recalled for aircraft noise in the next morning. In this case, they will dominate the assessment of annoyance following noise-induced sleep disturbances. This may disturb sleep, and by definition lead to an increased degree of annoyance (Quehl and Basner, 2005, 2006, 2008).

\section{Combined effects of nocturnal aircraft, road, and rail traffic noise and annoyance}

Taking into account highly annoyed persons according to the Schultz criterion (Schultz, 1978), aircraft noise annoyance in the AIRA, AIRO, and AIRORA conditions was highest. In the paired comparisons, the double exposure with aircraft and railway noise and the triple exposure with all three traffic noises induced a significantly higher aircraft noise annoyance than the single aircraft noise exposure. Thus, aircraft noise annoyance was amplified by the existence of a second or third traffic noise source. Other investigations on the annoying impact of transportation noise (at day) already pointed out that a separate assessment of single traffic noise sources may not be adequate for the evaluation of multiple traffic 
noise impacts (Ortscheid and Wende, 2002a). However, these studies did not apply to nocturnal noise exposure.

\section{B. Nocturnal traffic noise and morning cognitive performance}

\section{General effects of nocturnal aircraft, road, and rail traffic noise and cognitive performance}

Nocturnal aircraft, rail, and road traffic noise led to impairments in cognitive performance the following morning. Pooled data of nocturnal traffic noise showed a significant increase in reaction time of up to $6 \mathrm{~ms}$ compared to performance after a night without noise exposure in the PVT only. This quite small degradation in reaction time is in line with former studies on nocturnal aircraft noise on performance using this PVT (Elmenhorst et al., 2010) where a significant increase in reaction time due to nocturnal aircraft noise ranged around $4 \mathrm{~ms}$. In another study on partial sleep deprivation, four nights with sleep restricted to $5 \mathrm{~h}$ per night resulted in an impairment in PVT reaction time between 5.7 to $8.8 \mathrm{~ms}$ (Elmenhorst et al., 2009). Accordingly, reaction time impairments as found in the present study are comparable with those under partial sleep deprivation. The effects of the present study on sleep are reported in detail in Basner et al. (2011). The observed effects on sleep are supported by another study on nocturnal aircraft noise effects in which the noise exposure led to sleep fragmentation and a moderate partial sleep deprivation (Basner et al., 2006). In a study on the effects of nocturnal railway noise on performance, small but significant increases in reaction time were found in a simple task which resembles the MST. False alarms and omissions were not affected by noise disturbed nights as in our study (Bonnefond et al., 2008). However, performance decrements were not found in an attentional network task. Investigations on the effects of nocturnal road, rail, and aircraft noise have shown increased reaction times in a switch task as a general noise effect, whereas the error rate was again constant (Marks and Griefahn, 2007).

\section{Combined effects of nocturnal aircraft, road, and rail traffic noise and cognitive performance}

Former studies on nocturnal traffic noise and performance presented trends but were not able to confirm significant performance deteriorations. In the present investigation performance did not differ between the traffic noise sources. Furthermore, combined traffic noise exposure patterns did not lead to stronger performance impairments than the single exposure conditions; effects were less than additive. Sleep disruptions caused by different traffic noise sources seem to be uniform in the resulting performance decrements the following day. Nevertheless, some of the traffic noise sources led to significant performance declines compared to patterns without noise exposure as was to be expected from the results of the general noise effect (pooled data). The separate exposure to aircraft noise had the strongest effect on performance. This is most probably a chance finding, since the same number and $L_{\mathrm{AS} \text {, max }}$ of aircraft noise events in combination with other traffic noise events is supposed to have at least the same degree in performance alteration. However, in a study on the effects of road, rail, and aircraft noise on performance and blink rate, the authors have reported a decrease in blink rate only in relation to aircraft noise, but not in relation to the noise levels, which hints at a higher effort to perform the task after aircraft noise exposure (Breimhorst et al., 2009). Concerning the subjective noise perception, in a recent meta-analysis a dose-response relationship between average night-time noise exposure and self-reported sleep disturbances revealed aircraft noise as the most disturbing traffic noise source (Miedema and Vos, 2007). Regarding objective polysomnographical dose-response relationships, rail noise induced the most severe sleep fragmentation, whereas aircraft noise showed the least effects on sleep continuity (Marks et al., 2008) or awakening probability (Basner et al., 2011; Elmenhorst et al., 2012). Performance in PVT was best after the adaptation night, even better than under the baseline condition which was included in the cross-over design. One night without noise after several nights with noise exposure seems not enough to eliminate cumulative carry-over effects. An additional baseline night following the adaptation night is missing, so performance after the adaptation night was used as a second condition which was not influenced by noise. As has been reported before (Elmenhorst et al., 2010), increasing numbers of noise events and increasing $L_{\mathrm{AS} \text {,eq }}$ led to performance impairments in PVT in the present study as well. The subjective workload ratings ranged in the low category during adaptation, baseline, and noise conditions. Noise exposure in general did not alter the experienced workload level. The combination of aircraft and rail traffic noise (AIRA) during the night had the strongest impact on subjective workload the following day. Nevertheless, workload rating remained in the low category.

\section{Limitations}

Laboratory and field studies differ in their strengths and weaknesses. Field studies are performed in natural settings and thus have a high external and ecological validity, contrary to laboratory studies performed under controlled conditions. In the present case, the investigation under laboratory conditions allowed systematic testing of the impact of type of transportation noise exposure and of combined effects (high internal validity). However, studies of noise annoyance in the laboratory are limited, since the evaluation of noise with respect to its disturbing potential becomes the main task of the subjects, which does not necessarily refer to the natural conditions in the domestic environment and thus may result in different annoyance ratings.

\section{CONCLUSIONS}

For noise annoyance a ranking in the size of effects was found that was caused by nocturnal air, rail, and road traffic that was not reflected in cognitive performance. Regarding the annoyance due to nocturnal aircraft noise a significant interactive effect was found, i.e., multiple traffic noise exposure (i.e., double exposure with aircraft and railway noise 
and the triple exposure with all three traffic noises) was more annoying than the single aircraft noise pattern.

Nocturnal traffic noise led to small but significant impairments in daytime cognitive performance. These increments seemed to be independent of the noise of specific traffic noise sources or the combination of traffic noise sources when $L_{\mathrm{AS} \text {,eq }}$ and number of noise events were kept constant. One interposed night without noise was not sufficient to restore performance levels. Further studies should be complemented with an additional noise free night in the beginning and ending of the study to gather more information about cumulative noise effects.

Further investigations on interactive effects of multiple traffic noises at night are needed.

\section{ACKNOWLEDGMENTS}

E.-M.E and J.Q. contributed equally to this publication. The authors gratefully thank their colleagues in the division of Flight Physiology for their support of this work as well as the subjects for their willingness to participate in the studies. This study was part of the DLR/HGF-project "Quiet Air Traffic II."

AGARD (1989). "Human performance assessment methods," AGARDOGRAPH No. 308, report No. AGARD-AG-308, North Atlantic Treaty Organization, Advisory Group for Aerospace Research and Development, Neuilly-Sur-Seine, AGARD, pp. 33-37.

Babisch, W. (2011). "Cardiovascular effects of noise," Noise Health 13, 201-204.

Basner, M., Isermann, U., and Samel, A. (2006). "Aircraft noise effects on sleep: Application of the results of a large polysomnographic field study," J. Acoust. Soc. Am. 119, 2772-2784.

Basner, M., Mueller, U., and Elmenhorst, E. M. (2011). "Single and combined effects of air, road, and rail traffic noise on sleep and recuperation," Sleep 34, 11-23.

Basner, M., and Siebert, U. (2006). "Markov-Prozesse zur Vorhersage fluglärmbedingter Schlafstörungen" ("Markov processes for predicting aircraft noise induced sleep disturbances"), Somnologie 10, 176-191.

Berglund, B., Lindvall, T., and Schwela, D. H. (2000). Guidelines for Community Noise (World Health Organization, Geneva), pp. 1-159.

Bonnefond, A., Saremi, M., Rohmer, O., Hoeft, A., Eschenlauer, A., Eschenlauer, R., Muzet, A., and Tassi, P. (2008). "Effects of nocturnal railway noise on subjective ratings of sleep and subsequent cognitive performance," Somnologie 12, 130-138.

Breimhorst, M., Marks, A., Robens, S., and Griefahn, B. (2009). "Blink rate during tests of executive performance after nocturnal traffic noise," Noise Health 11, 217-222.

Dinges, D. F., and Powell, J. W. (1985). "Microcomputer analysis of performance on a portable, simple visual RT task during sustained operations," Behav. Res. Methods Instrum. Comput. 17, 652-655.

Elmenhorst, D., Elmenhorst, E. M., Luks, N., Maass, H., Mueller, E. W., Vejvoda, M., Wenzel, J., and Samel, A. (2009). "Performance impairment during four days partial sleep deprivation compared with the acute effects of alcohol and hypoxia," Sleep Med. 10, 189-197.

Elmenhorst, E. M., Elmenhorst, D., Wenzel, J., Quehl, J., Mueller, U., Maass, H., Vejvoda, M., and Basner, M. (2010). "Effects of nocturnal aircraft noise on cognitive performance in the following morning: Doseresponse relationships in laboratory and field," Int. Arch. Occup. Environ. Health 83, 743-751.

Elmenhorst, E. M., Pennig, S., Rolny, V., Quehl, J., Müller, U., Maaß, H., and Basner, M. (2012). "Examining nocturnal railway noise and aircraft noise in the field: Sleep, psychomotor performance, and annoyance," Sci Total Environ. 424, 48-56.

European Environment Agency (2010). "Good practice guide on noise exposure and potential health effects," EEA technical report No. 11/2010, pp. 3-36.
Evans, G. W., and Lepore, S. J. (1997). "Moderating and mediating processes in environment-behavior research," in Advances in Environment, Behavior, and Design. Towards the Integration of Theory, Methods, Research, and Utilization, edited by G. T. Moore and R. W. Marans (Environmental Design Research Associates, Oklahoma City), Vol. 4, pp. 255-285.

Felscher-Suhr, U., Guski, R., and Schuemer, R. (2000). "Internationale Standardisierungsbestrebungen zur Erhebung von Lärmbelästigung" ("International effort to standardize the inquiry of noise annoyance"), Z. Lärmbekämpfung 2, 68-70.

Fidell, S., Barber, D., and Schultz, T. J. (1991). "Updating a dosage-effect relationship for the prevalence of annoyance due to general transportation noise," J. Acoust. Soc. Am. 89, 221-233.

Fidell, S., Mestre, V., Schomer, P., and Berry, B. F. (2011). "A firstprinciples model for estimating the prevalence of annoyance with aircraft noise exposure," J. Acoust. Soc. Am. 130, 791-806.

Fidell, S., Sneddon, M., and Harrison, R. (2013). "Relative contributions of highway and neighborhood sources to outdoor and indoor residential noise," Noise Control Eng. J. 61, 205-218.

Fields, J. M. (1993). "Effect of personal and situational variables on noise annoyance in residential areas," J. Acoust. Soc. Am. 93, 2753-2763.

Fields, J. M., de Jong, R. G., Gjestland, T., Flindell, I., Job, R. F. S., Kurra, L., Lercher, P., Vallet, M., Yano, T., Guski, R., Felscher-Suhr, U., and Schuemer, R. (2001). "Standardized general-purpose noise reaction questions for community noise surveys: Research and a recommendationCommunity response to noise team of ICBEN," J. Sound Vib. 242, 641-679.

Fields, J. M., and Walker, J. G. (1982). "The response to railway noise in residential areas in Great Britain,” J. Sound Vib. 85, 177-255.

Griefahn, B., Marks, A., and Robens, S. (2006). "Noise emitted from road, rail and air traffic and their effects on sleep," J. Sound Vib. 295, 129-140.

Griefahn, B., Schuemer-Kohrs, A., Schuemer, R., Moehler, U., and Mehnert, P. (2000). "Physiological, subjective, and behavioral responses during sleep to noise from rail and road traffic," Noise Health $\mathbf{3}$, 59-71.

Guski, R. (1991). "Zum Anspruch auf Ruhe beim Wohnen" ("The claim of silence at the habitation”), Z. Lärmbekämpfung 38, 61-65.

Guski, R., Ising, H., Jansen, G., Költzsch, P., Scheuch, K., Schick, Schönpflug, W., and Spreng, M. (2004). "Fluglärm 2004-Stellungnahme des interdisziplinären Arbeitskreises für Lärmwirkungsfragen beim Umweltbundesamt" ( "Aircraft noise 2004 Statement of the interdisciplinary working team for noise questions at the German federal environmental agency"), Berlin, pp. 1-116.

Hart, S. G., and Staveland, L. E. (1988). "Developement of NASA-TLX (Task Load Index): Results of empirical and theoretical research," in Human Mental Workload, edited by P. A. Hancock and N. Meshkati (Elsevier, Amsterdam), pp. 139-183.

Hoeger, R. (2004). "Aircraft noise and times of day: Possibilities of redistributing and influencing noise exposure," Noise Health 6, 55-58.

Jarup, L., Babisch, W., Houthuijs, D., Pershagen, G., Katsouyanni, K., Cadum, E. Dudley, M. L., Savigny, P., Seiffert, I., Swart, W., Breugelmans, O., Bluhm, G., Selander, J., Haralabidis, A., Dimakopoulou, K., Sourtzi, P., Velonakis, M., and Vigna-Taglianti, F. (2008). "Hypertension and exposure to noise near airports: The HYENA study," Environ. Health Perspect. 116, 329-333.

Marks, A., and Griefahn, B. (2005). "Railway noise-Its effects on sleep, mood, subjective sleep quality, and performance," Somnologie 9, 68-75.

Marks, A., and Griefahn, B. (2007). "Associations between noise sensitivity and sleep, subjectively evaluated sleep quality, annoyance, and performance after exposure to nocturnal traffic noise," Noise Health 9, 1-7.

Marks, A., Griefahn, B., and Basner, M. (2008). "Event-related awakenings caused by nocturnal transportation noise," Noise Control Eng. J. 56, $52-62$.

Matheson, M., Stansfeld, S., and Haines, M. M. (2010). "The effects of chronic aircraft noise exposure on children's cognition and health: 3 field studies," Noise Health 5, 31-40.

Miedema, H. M. E., and Oudshoorn, C. G. M. (2001). "Annoyance from transportation noise: Relationships with exposure metrics DNL and DENL and their confidence intervals," Environ. Health Perspect. 109, 409-416.

Miedema, H. M., and Vos, H. (1998). "Exposure-response relationships for transportation noise," J. Acoust. Soc. Am. 104, 3432-3445.

Miedema, H. M. E., and Vos, H. (2007). "Associations between selfreported sleep disturbance and environmental noise based on reanalyses of pooled data from 24 studies," Behavioral Sleep Med. 5, 1-20. 
Öhrstrom, E. (1995). "Effects of low levels of road traffic noise during night: A laboratory study on number of events, maximum noise levels and noise sensitivity," J. Sound Vib. 179, 603-615.

Oliva, C. (1998). Belastungen der Bevölkerung durch Flug- und Straßenlärm: Eine Lärmstudie am Beispiel der Flughäfen Geneva und Zürich (Burden of Residents by Air and Road Traffic Noise: A Noise Study at the Airports Genf and Zurich) (Duncker und Humblot, Berlin), pp. 1-195.

Ortscheid, J., and Wende, H. (2001). "Lärmwirkung und Lärmsummation" ("Effects of noise and summation of noise"), Z. Lärmbekämpfung 48, 75-76.

Ortscheid, J., and Wende, H. (2002a). "Lärm. Erfassung und Bewertung" ("Noise. Recording and evaluation"), Z. Umweltrecht 3, 185-189.

Ortscheid, J., and Wende, H. (2002b). "Lärmbelästigung in DeutschlandErgebnisse einer repräsentativen Umfrage" ("Noise annoyance in Germany-Results of a representative survey”) Z. Lärmbekämpfung 49, $41-45$.

Ortscheid, J., and Wende, H. (2004). "Lärmbelästigung in DeutschlandErgebnisse der Befragung im Jahr 2004" ("Noise annoyance in Germany-Results of a survey in the year 2004"), Z. Lärmbekämpfung 53, 24-30.

Quehl, J., and Basner, M. (2005). "Belästigung durch Nachtfluglärm im Schlaflabor: Dosis-Wirkungskurven" ("Annoyance due to nocturnal aircraft noise in the sleep laboratory: Dose-respose curves") Z. Lärmbekämpfung 52, 38-45.
Quehl, J., and Basner, M. (2006). "Annoyance from nocturnal aircraft noise exposure: Laboratory and field-specific dose-response curves," J. Environ. Psychol. 26, 127-140.

Quehl, J., and Basner, M. (2008). "Nächtlicher Flug-, Straßen- und Bahnlärm: Belästigungsunterschiede und kumulative Wirkungen" ("Nocturnal air, road and rail traffic noise: Differences in annoyance and cumulative effects"), Z. Lärmbekämpfung 6, 240-245.

Schapkin, S. A., Falkenstein, M., Marks, A., and Griefahn, B. (2006). "Executive brain functions after exposure to nocturnal traffic noise: effects of task difficulty and sleep quality," Eur. J Appl. Physiol. 96, 693-702.

Schomer, P., Mestre, V., Fidell, S., and Berry, B. F. (2012). "Role of community tolerance level (CTL) in predicting the prevalence of the annoyance of road and rail noise," J. Acoust. Soc. Am. 131, 2772-2786.

Schultz, T. J. (1978). "Synthesis of social surveys on noise annoyance," J. Acoust. Soc. Am. 64, 377-405.

Stallen, P. J. (1999). "A theoretical framework for environmental noise annoyance," Noise Health 1, 69-80.

Tegeder, K. (2001). "Summation von Schallpegeln verschiedener Geräuscharten" ("Summation of sound pressure levels of different noise sources”), Z. Lärmbekämpfung 48, 72-74.

VDI (2013). 3722: "Effects of traffic noise-Part 2: Characteristic quantities in case of impact of multiple sources," Beuth Verlag, p. 2.

Wilkinson, R. T., and Campbell, K. B. (1984). "Effects of traffic noise on quality of sleep: Assessment by EEG, subjective report, or performance the next day," J. Acoust. Soc. Am. 75, 468-475. 